\title{
Estimating the costs of providing voluntary medical male circumcision in South Africa
}

Project SOAR

Follow this and additional works at: https://knowledgecommons.popcouncil.org/departments_sbsr-hiv

Part of the Demography, Population, and Ecology Commons, Family, Life Course, and Society Commons, and the International Public Health Commons How does access to this work benefit you? Let us know!

\section{Recommended Citation}

Project SOAR. 2016. "Estimating the costs of providing voluntary medical male circumcision in South Africa," Research brief. Washington, DC: Population Council. 


\section{Estimating the Costs of Providing Voluntary Medical Male Circumcision in South Africa}

\section{Background}

The South African Government introduced voluntary medical male circumcision (VMMC) as an HIV prevention intervention in 2010 based on the compelling evidence that VMMC reduces men's risk of becoming HIV infected by approximately 60 percent [1]. However, only 46.4 percent of males ages 15 and older were circumcised by the end of 2012 [2].

South Africa's VMMC program performed 1.9 million male circumcisions between 2010 and early 2015 . While program growth to date has been robust, this represents less than half of the current target of 4.3 million circumcisions expected to be completed by 2016 . To inform strategic planning for continued scale-up of its VMMC program and better understand cost drivers and cost variances across provinces, the South African National Department of Health in 2014 requested estimates of the unit cost of VMMC and the level of current spending for VMMC demand creation.

The objectives of this study were to:

- Estimate the unit cost to provide VMMC.

- Assess cost drivers and cost variances across provinces and different VMMC service delivery modes.

- Evaluate the costs associated with mobilizing and motivating men and boys to access VMMC services.

\section{Methods}

Data were collected at 33 government and PEPFARsupported VMMC facilities across eight of South Africa's nine provinces (all provinces except North West). Clients' out-of-pocket costs and demographic data were systematically collected through interviews with 190 VMMC clients or their caregivers (for minor

\section{Key Messages}

- The unit cost per circumcision performed in South Africa in 2014 was R1,431 (US\$132), ranging from $\mathrm{R} 1,309$ (US\$121) in health centers and clinics to R1,710 (US\$158) in public hospitals. The VMMC unit cost was largely driven by direct labor costs ( 43 percent), medicines and consumables (24 percent), continuous quality improvement (13 percent) and indirect labor (11 percent).

- Direct cost of labor would have been reduced by 17 percent (representing 7 percent of VMMC unit cost per circumcision) if task shifting were implemented, resulting in R163 million (US\$15 million) in savings in 2015 .

- VMMC clients reported spending, on average, R100 (US\$9.23) on transportation to access VMMC services, which is quite substantial.

- About R154 million (US\$15 million) was spent in 2014 on VMMC demand creation, representing 26 percent of all 2014 PEPFAR VMMC expenditures.

clients) at 25 of the 33 facilities. Facility site selection criteria included geographic area in the province (e.g., urban, peri-urban, or rural sites) and mode of service delivery (e.g., fixed vs. fixed with outreach services).

Cost data for circumcision kits, medications and other consumables, equipment and furniture, vehicles, overhead, and continuous quality improvement (CQI) were retrospectively collected from sites for the period January to December, 2014. When data were not available, robust efforts were made to obtain 
information from the district, provincial, or national levels within the Department of Health or from PEPFAR implementing partners. The human resources, financial data, and utilization data were gathered from facilities and implementing partners. Costs for indirect labor (labor for administrative/support staff who were not directly providing VMMC services) were allocated based on the ratio of VMMC clients to total clients at each site.

\section{Results}

\section{Unit cost by mode of service delivery}

The unit cost was R1,431 (US\$132) per circumcision performed in 2014. Of the 33 sites that were surveyed, 25 were "fixed only" and 8 were "fixed with an outreach component."

Figure 1 shows that the difference between these two modes of service delivery is small. The largest components of unit costs are clinical labor, 43 percent; consumables, 24 percent (including the cost of male circumcision kits); CQI, 13 percent; and indirect labor 11 percent. The remaining 9 percent are represented by overhead, training, equipment, and vehicles costs. Demand creation was not included in the unit cost because many of these costs were incurred outside the facility level (e.g., radio advertisements).

\section{Figure 1 Unit cost by service delivery model}

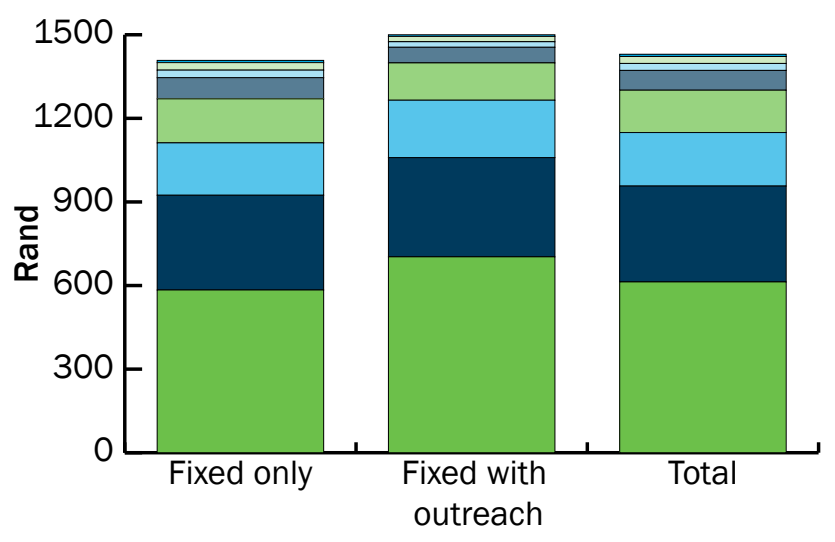

\begin{tabular}{|ll|}
$\square$ Direct labor & $\square$ Overhead \\
$\square$ Consumables & $\square$ Training \\
$\square$ CQI & $\square$ Equipment \\
$\square$ Indirect labor & $\square$ Vehicles \\
\hline
\end{tabular}

\section{Unit cost by scale}

Figure 2 shows the relationship between the number of circumcisions performed at a facility in 2014 and the unit cost of each circumcision performed. About 45 percent of all sites had fewer than 1,000 circumcisions per year. The unit cost of these lower volume facilities was R1,473 (US\$136). While about 21 percent of all sites reported more than 3,000 circumcisions per year, these higher volume sites had a unit cost of R1,231 (US\$114). The red line in Figure 2 shows a statistically significant inverse relationship between volume and unit cost $(p<.05)$, with sites that have higher numbers of VMMC clients generally having a lower unit cost. However, scale does not fully explain the variation $\left(R^{2}=0.12\right)$ in unit cost because some lower volume sites do have a low unit cost, while some higher volume sites have a high unit cost.

Of the 33 sites where data were collected, 11 were hospitals and 22 were health centers/clinics. The unit cost at hospitals was R1,666 (US\$154) compared to $\mathrm{R} 1,313$ (US\$121) at health centers/clinics. This difference is statistically significant $(p=.009)$ and attributable to higher labor costs (both direct and indirect) at hospitals, relative to health centers and clinics.

\section{Task shifting}

Task shifting is the re-assignment of activities performed by more expensive clinical staff, such as

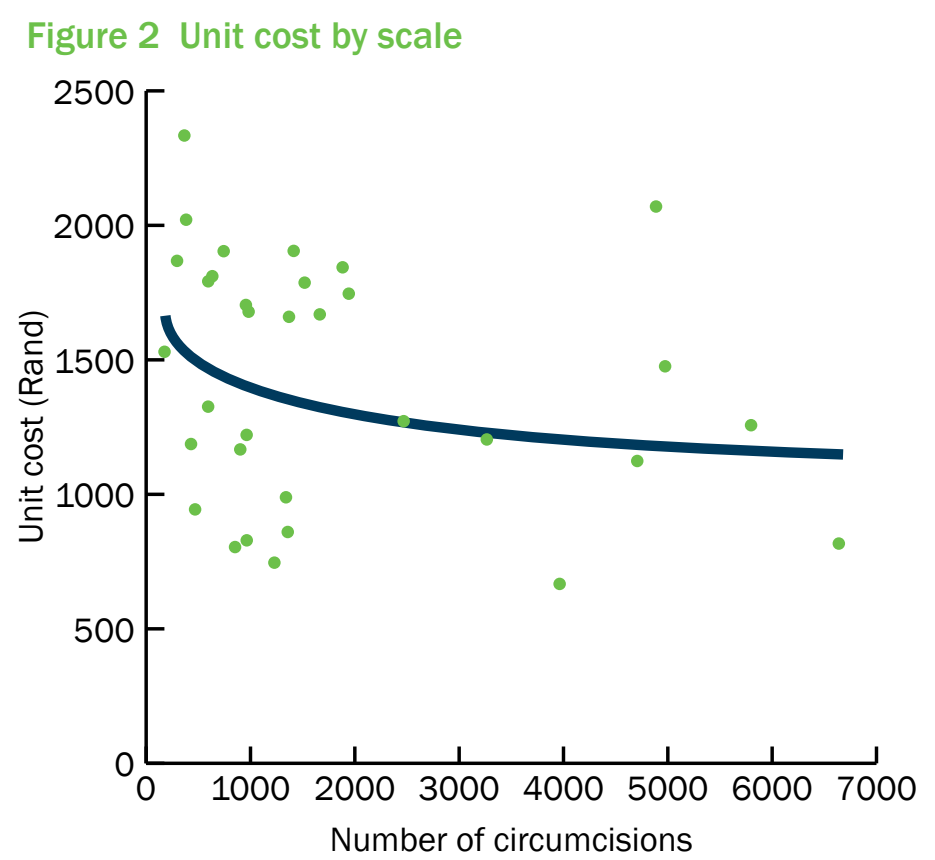


doctors and clinical associates, to less expensive staff such as nurses. The current labor unit cost for male circumcision is estimated to be R613 (US\$56.60). If doctors and clinical associates were replaced by professional nurses, this could be reduced to R511 (US\$47.18) per circumcision, a savings of R102 (US\$9.41), or 17 percent of direct labor costs (representing 7 percent of the total unit cost per circumcision). In 2015, the Government of South Africa established an ambitious target of performing 1.6 million circumcisions and, if the cost savings from task shifting was achieved, the total savings in 2015 alone would have been R163.2 million (US\$15 million).

\section{Clients' out-of-pocket costs}

While the average age of VMMC clients is 22 years, about 42 percent are younger than 18 years, with the largest proportion of minor clients between 10 and 15 years of age (29 percent). Although the cost of circumcision itself is free, clients and caregivers both reported out-of-pocket payments for transportation (from pre-surgery to future follow-up visits) in six of the eight provinces surveyed. The average client outof-pocket expense was R100 (US\$9.23), ranging from R84 (US\$7.76) in Northern Cape to R152 (US\$14.02) in Mpumalanga (Figure 3). Transportation expenses do not differ substantially based on the geographical location of facilities; urban R114 (US\$10.53), peri-urban R90 (US\$8.31), and rural R117 (US\$10.80).

\section{Figure 3 Clients out-of-pocket transportation} expenses by province

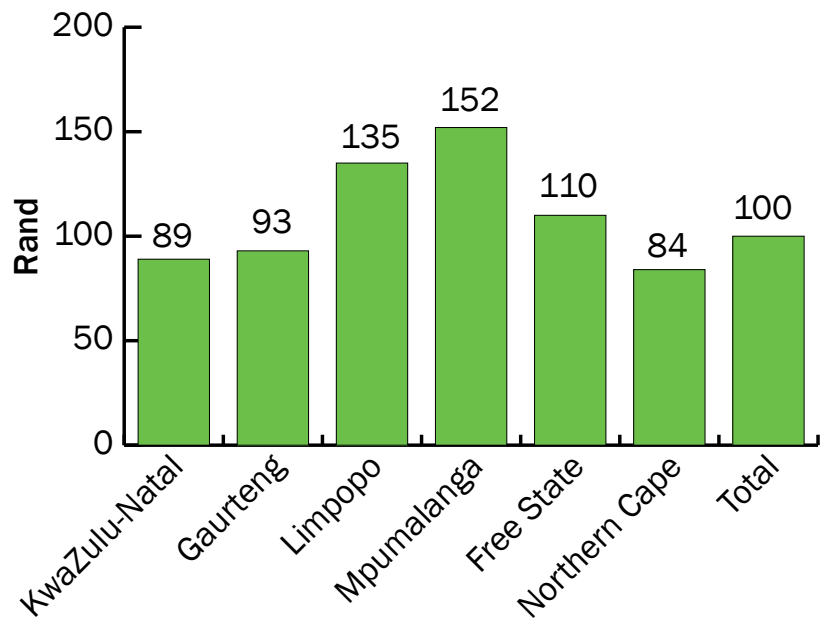

Province
Lost workdays were reported by only eight clients (4 percent). Other sources of out-of-pocket expenditures included childcare costs or expenditures on miscellaneous items such as food or medicine for wound care treatment, reported respectively by 1 and 20 clients.

Clients at outreach sites were less likely to report transport costs (41 percent) compared to clients at fixed facilities with no outreach program (71 percent).

\section{Demand creation}

A total of R154 million or US\$14.2 million (including PEPFAR and other funding sources) was estimated to have been spent on VMMC demand creation from January to December 2014, representing 26 percent of resources spent by PEPFAR on male circumcision in South Africa that year. Figure 4, which accounts for R149 million (US\$13.76 million) that could be disaggregated by spending category, shows that personnel/community mobilizers (36 percent) and mass/ small media (35 percent) were the major drivers of the demand creation spending.

\section{Conclusions}

This study provides a number of important findings about the cost of male circumcision in South Africa. First, the unit cost of male circumcision was R1,431 (US\$132). South Africa could have saved as much as R163 million (US\$15 million) in 2015 if the govern-

\section{Figure 4 Demand creation by major cost category}

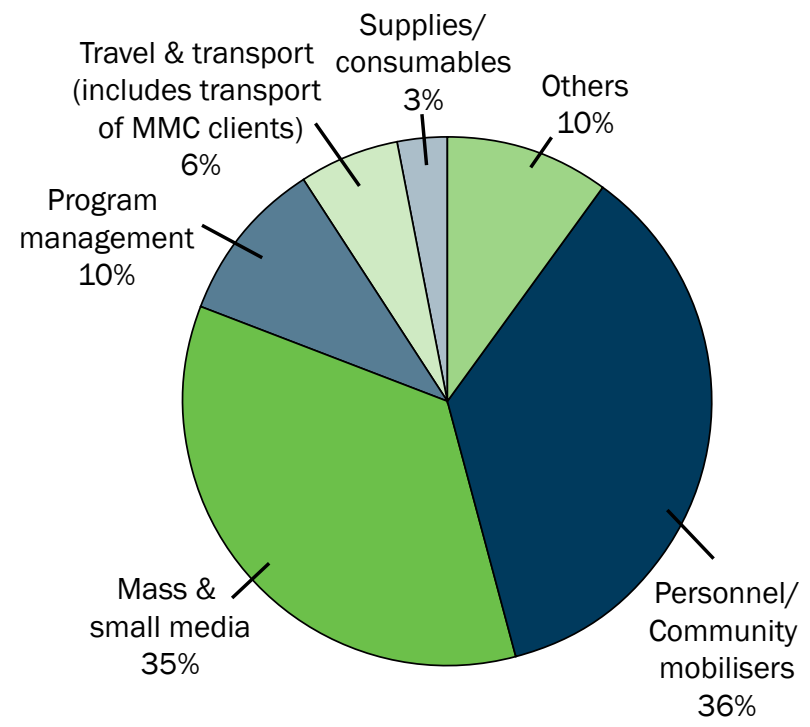

Estimating the costs of providing VMMC in South Africa 
ment had instituted task shifting to achieve its ambitious target of performing 1.6 million circumcisions in that year alone.

As expected, there were also economies of scale associated with VMMC. Higher volume sites generally had a lower unit cost, whereas lower volume sites generally had a higher unit cost. This indicates that there are potential efficiencies which can be achieved by focusing limited resources on high volume sites.

VMMC delivery at health centers and clinics appeared to be less expensive than at hospitals: R1,309 (US\$121) vs. R1,710 (US\$158). This was largely driven by the higher cost of direct labor at hospitals. Overall, the greatest cost drivers were direct labor, consumables, CQI, and indirect labor.

\section{Clients and caregivers of South Africa's VMMC} program on average spent R100 (US\$9.23) on transport, which is quite substantial. In 2011, poor and non-poor households in South Africa only spent respectively $\mathrm{R} 7$ (US\$0.65) and R63 (US\$5.82) daily on transportation [3]. Consequently, spending R100 (US\$9.23) on transport to access VMMC services, given other competing household priorities such as electricity, could represent a significant barrier to creating demand for VMMC. But outreach services can help reduce this barrier, since clients accessing these services were less likely to report transport costs than clients at fixed facilities. Transportation costs tended to be higher in some provinces (e.g., Mpumalanga), but generally did not vary between urban, peri-urban, and rural facilities.

A key finding of this study was that in 2014, about R154 million (US\$14.2 million) was spent on VMMC demand creation. What remains uncertain is whether this level of spending on demand creation is appropriate, and whether the allocation of resources within the demand creation program is effective. Further studies should examine linkage of service provision to demand creation activities (i.e., tracking whether people reached through social mobilization and mass media activities accessed VMMC services) to estimate the unit cost of demand creation per person circumcised.

The results of this study provide a comprehensive analysis of the unit cost of providing VMMC in South Africa. These results will be used to inform strategic planning for continued scale-up of VMMC and to identify the resources required to sustain the VMMC program. Study findings will also enable the South African Government to understand cost drivers and cost variances across the provinces and across different modes of VMMC service delivery.

\section{Acknowledgments}

This brief prepared by M. Tchuenche, S. Forsythe (Project SOAR, Health Policy Project \& Avenir Health, Washington, DC), E. Palmer (Health Policy Project, Palladium Consultant), V. Haté (George Washington University, Washington, DC), A. Thambinayagam (U.S. Agency for International Development (USAID), Pretoria, South Africa), D. Loykissoonlal (National Department of Health, Pretoria, South Africa), and E. Njeuhmeli (USAID, Washington, DC) was made possible through the U.S. President's Emergency Plan for AIDS Relief (PEPFAR) with USAID under the Cooperative Agreement Health Policy Project, Agreement No. AID-OAA-A-10-00067, beginning 30 September 2010, Cooperative Agreement Project SOAR (Supporting Operational AIDS Research), number AID-OAA-14-00060, and Cooperative Agreement Strengthening High Impact Interventions for an AIDS-free Generation, number AIDOAA-A-14-00046. The Health Policy Project is implemented by Palladium (formerly Futures Group), in collaboration with Plan International USA, Avenir Health (formerly Futures Institute), Partners in Population and Development, Africa Regional Office, Population Reference Bureau, RTI International, and the White Ribbon Alliance for Safe Motherhood. The funder was involved in study design, decision to publish, and preparation of the manuscript. The findings and conclusions of the study do not necessarily represent the views or positions of PEPFAR, USAID, the South African National Department of Health, or the U.S. Government.

\section{References}

1. Auvert, B. et al. 2005. "Randomized, controlled intervention trial of male circumcision for reduction of HIV infection risk: The ANRS 1265 trial," PLoS Med 2(11): e298.

2. Shisana, O. et al. 2014. South African National HIV Prevalence, Incidence and Behaviour Survey, 2012. Cape Town: HSRC Press.

3. STATSSA. Poverty Trends in South Africa: An examination of absolute poverty between 2006 and 2011. http://www. statssa.gov.za/?p=2564, 2011. Accessed Jan 29, 2016. funded by the American people through the U. S. President's Emergency Plan for AIDS Relief through USAID (Agreement No. AID-OAA-A-14-00060). Project SOAR is able to accept funding from all USAID accounts.

Population Council leads the Project SOAR consortium in collaboration with Avenir Health, Elizabeth Glaser Pediatric AIDS Foundation, the Johns Hopkins University, Palladium, and The University of North Carolina at Chapel Hill.
Project SOAR/Population Council

4301 Connecticut Avenue, NW, Suite 280

Washington, DC 20008

Tel: +1 2022379400

e-mail: ProjectSOAR@popcouncil.org popcouncil.org/ProjectSOAR

@Population Council, July 2016 